Research Article

\title{
Evaluation of Informatization Performance of Construction Industrialization EPC Enterprises in China
}

\author{
Fuyi Yao $\mathbb{D},{ }^{1}$ Yingbo Ji $\left(\mathbb{D},{ }^{2}\right.$ Hong Xian Li $\left(\mathbb{D},{ }^{3}\right.$ Guiwen Liu, ${ }^{1}$ Wenjing Tong, ${ }^{2}$ Yan Liu, ${ }^{2}$ \\ and Xiaowei Wang ${ }^{1}$ \\ ${ }^{1}$ School of Management Science and Real Estate, Chongqing University, Chongqing 400044, China \\ ${ }^{2}$ School of Civil Engineering, North China University of Technology, Beijing 100144, China \\ ${ }^{3}$ School of Architecture and Built Environment, Deakin University, Geelong Vic 3220, Australia \\ Correspondence should be addressed to Yingbo Ji; yingboji@126.com
}

Received 23 September 2019; Revised 7 December 2019; Accepted 26 December 2019; Published 22 January 2020

Academic Editor: Heap-Yih (John) Chong

Copyright (c) 2020 Fuyi Yao et al. This is an open access article distributed under the Creative Commons Attribution License, which permits unrestricted use, distribution, and reproduction in any medium, provided the original work is properly cited.

\begin{abstract}
An enormous amount of investment has been spent towards informatization for the construction industrialization engineering, procurement, and construction (EPC) enterprises in China; however, the performance output remains uncertain. This paper aims to evaluate the informatization performance of the construction industrialization enterprises in China based on a proposed evaluation framework. The proposed framework entails a hierarchical input and output structure; the input metrics include 4 firstlevel and 17 second-level indicators, and the outputs include 6 first-level and 27 second-level indicators as the metrics, respectively. Survey and interview are utilized to collect data, with effective responses from thirty construction industrialization EPC enterprises. The informatization performance of these enterprises is evaluated using an improved D-FCA method, which incorporates the analytic hierarchy process (AHP), data envelopment analysis (DEA), and fuzzy comprehensive evaluation analysis (FCA). The research results indicate that all the surveyed enterprises meet the performance requirement, and $60 \%$ of the thirty enterprises show excellent performance, reaching A level, AA level, and AAA level. Furthermore, for those enterprises with DEA scores less than 1, which indicates inefficient use of the resources during the informatization process, strategies are proposed to improve the performance of these enterprises. This study contributes a comprehensive framework to evaluate the informatization performance of construction industrialization enterprises in China. The enterprises studied currently mainly come from some developed areas, and the overall situation for construction industrialization needs to be further studied in future research.
\end{abstract}

\section{Introduction}

The construction industry in China has been growing at a tremendous rate in recent years [1]. From 2006 to 2016, revenue increased from 4,156 billion yuan to approximately 19,357 billion yuan, with an annual growth rate of $36.58 \%$; and the total annual completed floor area of buildings in China exceeds 4.2 billion $\mathrm{m}^{2}$ as of 2016. A life cycle chain has formed encompassing various facets [2], including design, manufacturing, engineering construction, maintenance, operation, and deconstruction stages [3,4]. The construction industry has become the primary economic contributor among industrial sectors worldwide [5, 6], and this situation is especially prominent in China. However, several challenges are restricting the sustainable development of the construction industry in China, such as insufficient technologies, enormous consumption of resources, massive waste, low productivity, and a shortage of skilled labor. Therefore, industrial production systems are needed in order to reform the construction industry [7]. Industrialization of the construction process is a solution that can be implemented in order to mitigate these challenges.

Construction industrialization is defined as factorybased prefabrication within a controlled environment of components to be assembled on-site $[8,9]$. When compared to the conventional construction method, the benefits of industrialized construction include accelerated construction, improved quality, decreased material waste, and reduced 
worker injuries $[10,11]$. It also contributes to sustainability by reducing energy usage and reducing greenhouse gas emissions $[12,13]$. In addition, construction industrialization has gained much attention and support from the government in China, and the government has issued some favourable policies to develop construction industrialization; specifically, industrialized construction is mandatory for affordable housing and public buildings in some jurisdictions. It is expected that the total floor area built by means of industrialized construction in China will exceed 127 million $\mathrm{m}^{2}$ by the end of 2018 (Ministry of Housing and Urban-Rural Development of the People's Republic of China [14]).

Construction industrialization EPC enterprise refers to the enterprise which adopts the model of project general contracting and mainly involves the development, design, production, and construction of industrialized buildings [15]. The EPC model has become the most popular project delivery strategy for industrialized construction, which allows general contractors to control project design, procurement, and construction and offers the flexibility to provide socialized, specialized, and commercialized services [16]. In 2016, the government issued a document emphasizing that (1) the construction enterprise should adopt the EPC mode to optimize information management and realize the informatization and (2) the application of information technology in industrialized building should be strengthened, facilitating cooperation among the participants in various stages of the industrialized chain. Therefore, informatization construction is imperative, and the informatization performance evaluation of construction industrialization EPC enterprises has become a hot topic. However, the informatization level of enterprises in China continues to be low for several reasons. (1) While making a large investment toward enterprise informatization, the application value is ambiguous, and there is no stable income. Moreover, lower mean values indicate very little future investment with informatization for a given investment [17]. (2) There is no obvious help for the enterprise's development in the short term, and the enterprise does not have a clear understanding of the benefits of informatization [18]. (3) A measurable tool is lacking to measure the performance of construction industrialization, which is the primary obstacle to making an investment decision.

So, this research aims to evaluate the informatization performance of the construction industrialization EPC enterprises, and the detailed research objectives include the following:

(1) Constructing the index system of informatization performance evaluation, including input and output metrics, based on information "input-output"

(2) Proposing an improved D-FCA evaluation method, and constructing the informatization performance evaluation model of construction industrialization EPC enterprises

(3) Proposing strategies to improve the informatization performance of the enterprises based on the performance evaluation results

\section{Literature Review}

2.1. Enterprise Informatization. Enterprise informatization refers to enhancing and optimizing the business process management level of enterprises by using advanced information technology and modern management methods [19]. Porter and Millar [20] put forward the theory of strategic competitive advantage, which raised a debate about whether information technology can bring competitive advantage to enterprises. Information system emerged for integration as part of the organizational strategy [21] for business management and encompassing modules supporting organizational functional areas [22], and enterprises can save cost, improve corporate profits, and competitiveness through it [23]. In recent years, various information systems are proposed to integrate with technologies [24], such as supply chain management (SCM) [25], facility management system (FMS) [26], and enterprise resource planning (ERP) systems. The most representative case of enterprise information construction is ERP systems, which are used by many companies for providing a general work environment to integrate the core business management functions [27]. The detailed modules include financial accounting, inventory management, procurement management, sales management, cost management, and production planning [28]. Furthermore, for improving the efficiency and output productivity of enterprise information systems, scholars have carried out a lot of lateral research. Turetken et al. [29] developed a theoretical model to study the influential characteristics of enterprise information system user interfaces; Zelenkov [30] proposed a conceptual model of agility of enterprise information systems to implement future unpredictable changes of requirements; $\mathrm{Mu}$ and Kwong [31] studied the design of a flexible enterprise information system architecture with minimal integration cost by selecting components. Meanwhile, the construction industry is not an exception to the pervasion information revolution, such as creating intelligent construction enterprises for gaining and sustaining competitive advantage by adopting information technology $[32,33]$. However, the construction industry is a highly heterogeneous sector, with a great diversity of specialties and large disparities in the size of enterprises [34], and the informalization of construction enterprise is undertaken with different levels and performance.

The informalization of construction industrialization EPC enterprises has the following unique characteristics: (i) The informalization level is uneven due to the level of proficient qualification and business scale [35]. Construction industrialization EPC enterprise can be divided into four types: real estate development-oriented, design-oriented, component production-oriented, and construction-oriented enterprises. Different types of enterprises required different qualifications with different informalization levels. And Hong et al. [36] also pointed out that the size of the construction organization has a significant impact on information technology adoption. (ii) The informalization construction is separated into business management and project management with no appropriate integration [34]. Little emphasis is placed on the informatization of 
construction companies because it is difficult for ERP systems to achieve complete supply chain management and budget control. However, at the level of project management, building information modeling (BIM) is widely adopted to achieve high-quality and efficient construction and management in the life cycle [37], and numerous benefits have been reported by Hasan and Rasheed [38] and Kang and Choi [39]. BIM-based collaboration platforms have also been developed [40]. (iii) Enormous data are generated during the construction process but lacking full utilization [41]. Informalization construction is urgent and necessary for construction process to collect enormous data and analysis for developing exciting business applications, such as cost-benefit analysis and digital delivery. Although the construction of informalization has been carried out by many enterprises, information construction cost is high, and whether the cost inputs can bring benefit is still unknown [42]. Thus, another significant unique characteristic is the uncertain informatization performance of construction industrialization EPC enterprises.

2.2. Evaluation of Informalization Performance. The evaluation and construction of enterprise informalization are equally important, and a reasonable evaluation is crucial for further guiding informalization [43]. Many enterprises cannot correctly understand the informalization due to the poor understanding of IT construction, which leads to gaps in how to implement and evaluate enterprise informalization performance to meet their requirements [44]. Research has been conducted regarding the evaluation of enterprise informatization from various perspectives.

2.2.1. Investigating the Index System and the Performance Evaluation of the Enterprise Informalization. In 2002, the National Informatization Evaluation Centre of China issued a tentative scheme about a basic index of enterprise informalization to guide enterprises to evaluate the degree of informatization construction. Then, many researchers did many works next to this. Chand et al. [45] provided a balanced scorecard-based framework for evaluating the performance of ERP systems including financial, customer, internal process, and innovation and learning. Chen and Lin [46] proposed a fuzzy linguistic performance index based on a flow network model to evaluate the performance of an ERP system. Zhang et al. [19] presented a comprehensive evaluation index system, and the three key first-level indicator sets include current status, production management characteristics, and system functional requirements. Shen et al. [47] measured the ERP performance, and the first-level index includes financial perspective, customer perspective, innovation and learning, and internal business process. Yang and IOP [42] established the evaluation system from hardware and software security, information organization, information technology application and the profit, and information ability level. It can be concluded that the most research on enterprise informalization evaluation focuses on the ERP system, not the whole level of the enterprise; meanwhile, a specific evaluation for informatization performance of the construction industrialization EPC enterprises is lacking. Therefore, constructing the index system of informatization performance evaluation is necessary, including input and output metrics, which can clearly understand the consistency and effectiveness between input and output in the informatization process.

2.2.2. Selection of Evaluation Methods. An efficient evaluation method for enterprise informatization is equally important with the evaluation index system for guiding the evaluation of enterprise informatization performance. Chen and Lin [48] proposed a method based on a stochastic-flow network model to evaluate the performance of an ERP system. Zhang et al. [19] used the grey relative correlation analysis method and the grey clustering assessment technology to evaluate the level of enterprise informatization. Shen et al. [47] used the quantitative-balanced scorecard approach to measure the ERP performance. Other commonly used evaluation methods include AHP, economic value added (EVA), data envelopment analysis (DEA), and probability statistics (PS) [19]. Although these methods have been used successfully in some researches, some limitations still existed for a comprehensive evaluation of enterprise informalization, such as a higher requirement for much more data and limited to the decision-making of real-world enterprise informatization [49]. Therefore, a combined evaluation method needs to be developed for evaluating the comprehensive index system of the enterprise informatization performance. Based on the above literature review, it is found that research on the informatization evaluation of construction industrialization enterprises is missing, especially in China, and the performance of construction industrialization informatization is unknown. Moreover, a comprehensive evaluation method is required for the informatization evaluation of construction industrialization enterprises.

\section{Research Methodology}

This research entails qualitative and quantitative studies to evaluate the informatization performance of construction industrialization EPC enterprises: (1) the index system of informatization performance evaluation is established through qualitative studies. Based on the characteristics of the construction industrialization EPC enterprise, a series of methods are used to select the indexes, including reviewing related literature, performing frequency statistics, field surveys, and expert consultation. The index framework is then sorted and integrated by referring to the performance prism method and the national enterprise informatization evaluation index system. (2) A mixed quantitative method is applied to evaluate the informatization performance of construction industrialization EPC enterprises. The DEA method is a popular approach for ranking the decisionmaking units (DMUs) according to their performance based on its excellent data processing ability [50]. However, two shortcomings exist for DEA: one is preference relations cannot be addressed for decision-making problems and 
another is DEA just can classify the units into efficient and inefficient two groups, but it cannot further rank the efficient DMUs. However, the AHP method usually is used to derive preference relation [51], and FCA can tackle fuzziness or the problem of vague decision-making more efficiently [52]. Therefore, the AHP and FCA methods are introduced to compensate the shortcomings. An improved D-FCA aggregation method is applied to evaluate the informatization performance. The specific steps as follows: (i) the AHP method is used as the first step to determine the weight of the evaluation indicators; (ii) the DEA method is used as the second step to calculate the relative efficiency index of each enterprise; and (iii) the FCA method is used as the third step to calculate the evaluation results. The application process is presented in detail in Figure 1.

\section{Input and Output Metrics of Enterprise Informatization}

Based on the characteristics of the construction industrialization EPC enterprise, a series of methods are used to select the indexes such as reviewing related literature, performing frequency statistics, field surveys, and expert consultation. The index framework is sorted and integrated by referring to the performance prism method [53] and the national enterprise informatization evaluation index system. The index design mechanism is then established, which requires two dimensions with input and output metrics. Finally, following the principles of reasonable index level, quantitative and qualitative integration, objective, and mutual independence [54], a multilayer informatization performance evaluation index system is constructed for construction industrialization EPC enterprises.

The index system is divided into two indicator sets. The first is the input metrics, including 4 first-level and 17 second-level indicators, which refer to the investment collection of various resources in the process of enterprise informatization construction, including the internal planning and construction and the promotion of external environment of the enterprise. The second is the output, including 6 first-level and 27 second-level indicators as the metrics, which mainly refers to the growth of enterprise performance capability after the informatization construction. The index system is shown in Table 1.

\subsection{Input Metrics of Informatization}

4.1.1. Strategic Planning. It is necessary for the construction industrialization EPC enterprise to provide a comprehensive and feasible strategic plan for informatization construction. A plan of detailed investment and management objectives should match the present level of informatization. For this reason, four first-level indicators are set, including the informatization planning rationality and informatization management planning investment.

The scoring method is applied to score the value of the second-level indicators. Taking the strategic planning as an example, if a detailed investment and management objective for the enterprise's informatization is put forward, the recorded value is 100 points; if an overall plan is conducted along with a rationality analysis, the recorded value is 75 points; if only an overall plan is conducted, the recorded value is 50 points; and if no strategic plan has been conducted, the recorded value is 0 points. The other second-level indicators follow a similar method.

4.1.2. Infrastructure Establishment. The development of information infrastructure is vital to the enterprise's information construction; it is the basis of information activities, including constructing an information management system, setting up a network, and investing in hardware and software. The information management system primarily includes an investment control system and operation and maintenance system of which the perfection degree has a direct impact on the information activities. The setting up of a network aims to expand the information flow, which forms the basis to carry out internal and external work. The importance of the investment in hardware and software facilities is evident such that they are carriers and tools for all information activities.

4.1.3. Team Formation. Increasing attention has been paid to talent development in enterprise informatization construction. The key aspects include the proportion of information technology personnel among the total number of staffs, the level of informatization understanding and support from leaders, the quality of information culture and information level of the staff (which mainly refers to the proficiency degree in the operation of information equipment), the establishment of a sound personnel training system and supervision quality assessment system, and the expenditure of enterprise staff information training.

4.1.4. External Environment. In China, the development of construction industrialization is advancing rapidly, which indicates a series of unique characteristics: (i) The government has issued a significant number of policies to promote industrialized building, EPC mode, and application of information technology. (ii) There are several stakeholders for the enterprise, such as the government, the material supplier, and the factories. The information construction of each stakeholder directly affects the information flow transmission and its speed. (iii) Due to the popularization and application of information technology, the working environment of projects has changed. (iv) Construction industrialization has different production processes as components are prefabricated in factory. Moreover, due to significant regional differences in China, site selection has significant impacts on the benefits of projects and enterprises.

\subsection{Output Metrics of Informatization}

4.2.1. Financial Indicator. The financial indicator is the most direct economic efficiency indicator, but it is difficult to 


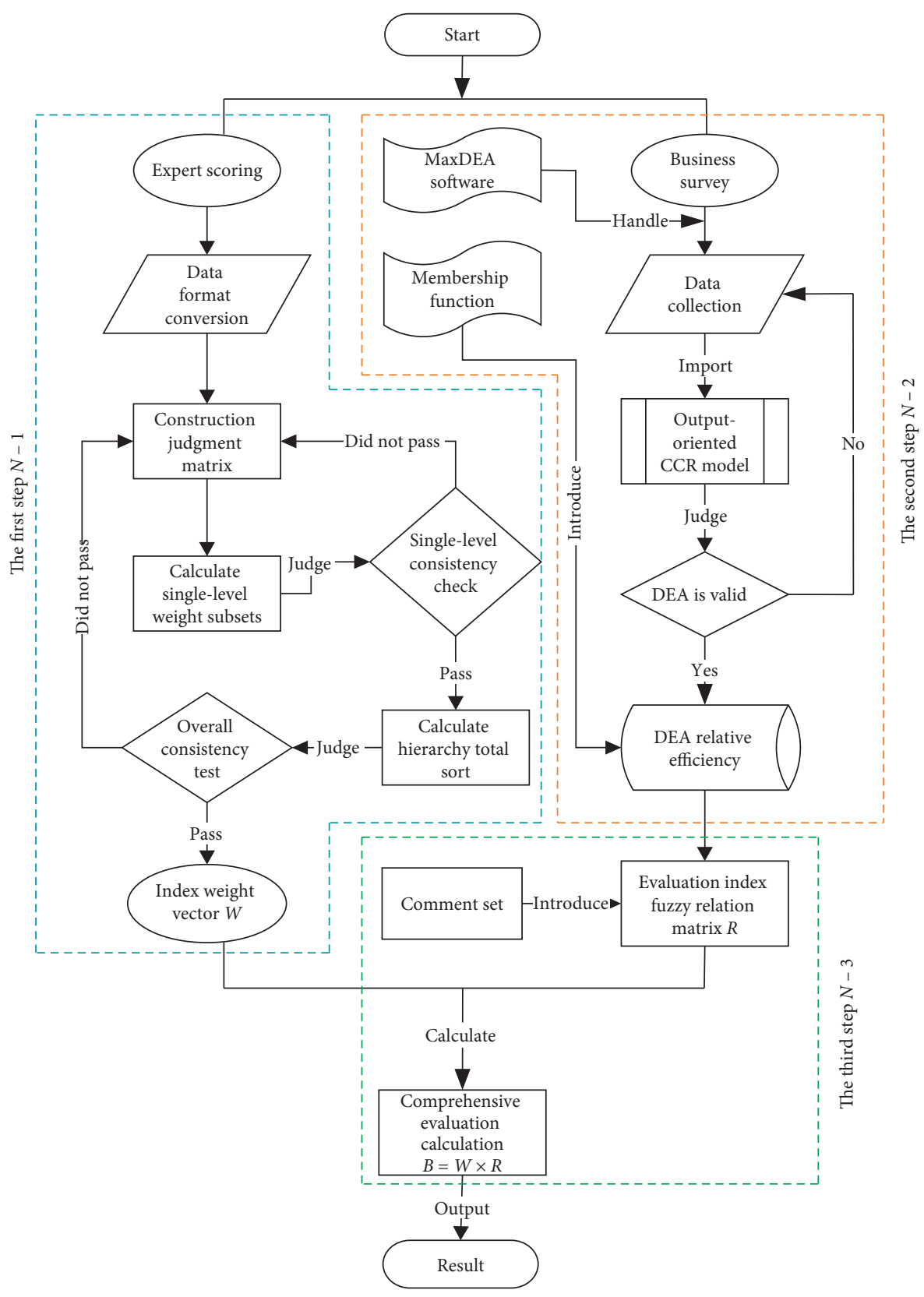

FIGURE 1: Research framework.

clarify. From the perspective of information technology application, it is mainly manifested in three aspects, namely, the profit rate of construction industrialization, the speed of enterprise capital circulation, and quantifiable economic benefits. Furthermore, the financial indicator is the one that greatly concerns management in the process of enterprise informalization construction.

4.2.2. Business Process Performance. Business process performance contains the richest contents. The information technology applications focus on two aspects: enterprise operation and project industrialization. Enterprise operation involves the level of fully digital paperless work, the level of office automation represented by the per capita occupancy of computers, the efficiency of using an ERP system in enterprise business, the routine information maintenance process, the reasonable business softness, and effective business management. Project industrialization includes the extent to which the information technology software functions can be realized in the overall life cycle, the level of information management of the project's life cycle, and the performance of final settlement speed and engineering dispute reduction.

4.2.3. Management Performance. Management performance mainly illustrates the level of enterprise management based on information data collection and processing. In order to determine this, the second-level indicator of internal resource integration is set to measure the ability to 
TABLe 1: Performance evaluation index system of construction industrialization enterprise.

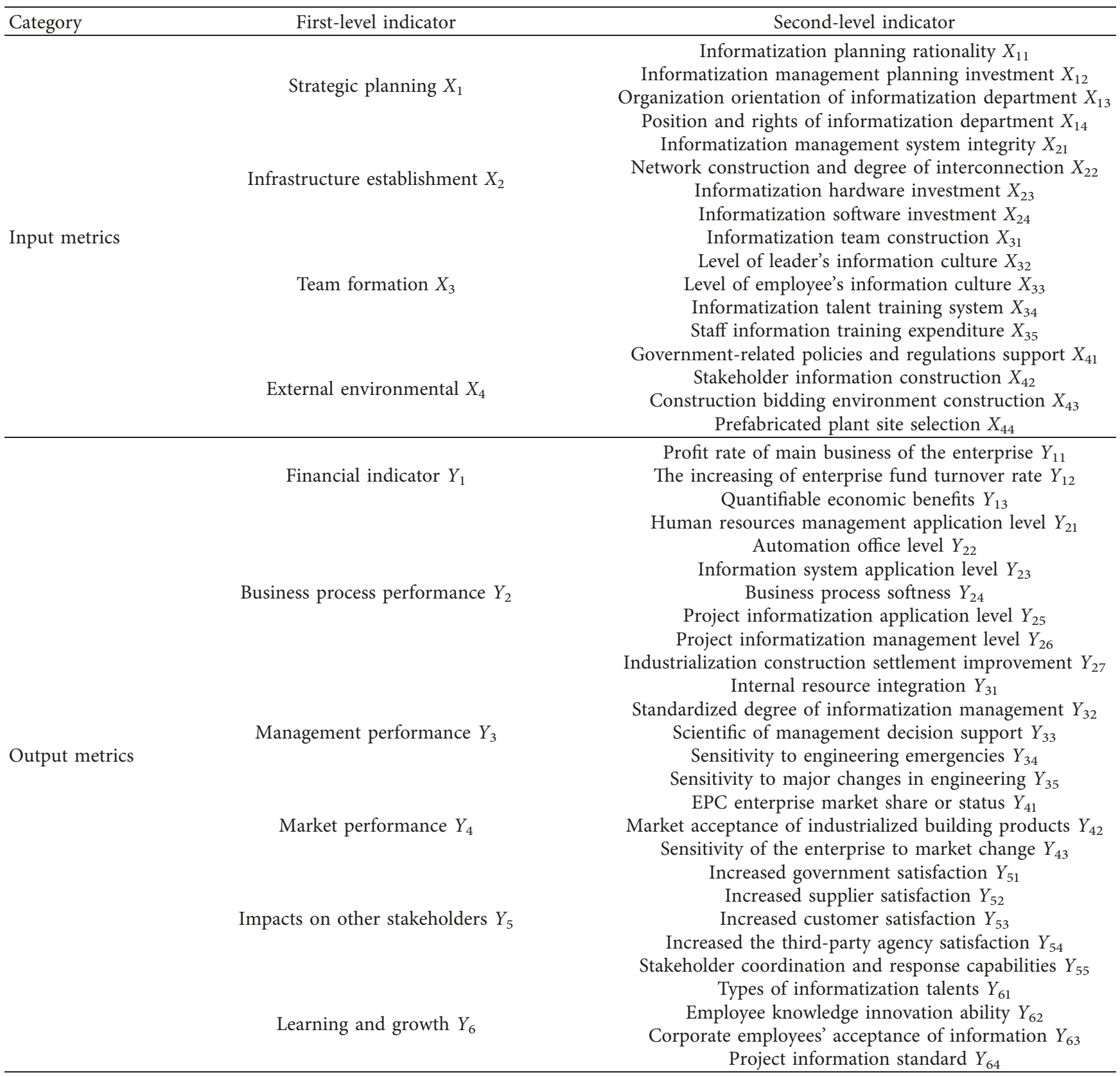

achieve information resource sharing and communicating effectively for each major task. The level of information management standardization is then investigated from the perspective of management system formulation and implementation. Also, the information technology application can provide basic data support for decision-making and engineering changing and improve the accuracy and scientific nature of the result.

4.2.4. Market Performance. The market is the source that determines the survival of an enterprise, especially for a construction industrialization EPC enterprise, which is determined by its production and cooperation attributes. Thus, for the informatization market performance, the main evaluation attributes include the enterprise's market share, the market recognition of industrialized building products or prefabricated components, and the sensitivity to market changes.

4.2.5. Impacts on Other Stakeholders. The first-level indicator of impacts on other stakeholders primarily refers to the level of informatization construction for the stakeholders of the construction industrialization EPC enterprise such as the government and the material suppliers. In addition, it is important to improve the coordination and responsiveness among stakeholders, and the stakeholders need to pay more attention to the application of information sharing and collaborative platform. 
4.2.6. Learning and Growth. Learning and growth are assessed from the perspective of informational knowledge output. This primarily includes the information-based talent training and its diversification, the knowledge innovation output, the employee recognition of informatization construction, and the information standard for construction industrialization projects.

\section{Comprehensive Evaluation Model}

Constructing a comprehensive informatization performance evaluation model is a vital step to measure the informatization level for construction industrialization EPC enterprises. An improved D-FCA method is developed to calculate the evaluation results of the informatization performance.

5.1. AHP Index Weight Calculation. AHP is a subjective empowerment method based on multiple expert scores for the evaluation of objects with several evaluation indicators and complicated structural relationships, which can resolve complex problems by organizing decision-makers' judgments into a hierarchy of forces that influence decision results $[55,56]$. This method mainly adopts the form of scales, makes full use of human experience and judgments, compares the relative importance of relevant factors at the same level, and synthesizes the measures to measure the decision goals $[57,58]$. The present research uses expert scoring methods to collect data and uses the AHP method to calculate the informatization performance evaluation index weights as follows.

A judgment matrix was constructed according to the relative importance scale of AHP. The 1-9 scale method was used to assign values. The specific scoring rules are presented in detail in Table 2; specifically, $A=\left(a_{i j}\right) n * n$, where $a_{i j}>0$, $a_{i j}=1 / a_{j i}$, and $a_{i i}=1$. Then, a one-time inspection was carried out at both the single level and overall. In order to judge whether the consistency of the matrix can be accepted, the maximum eigenvalue, $\lambda_{\text {max }}$, of the judgment matrix, $A$, is calculated as expressed in equation (1), and the consistency index, CI, and consistency ratio, CR, are also calculated as expressed in equations (2)-(4).

The judgment matrix:

$$
\begin{aligned}
& A=\left(a_{i j}\right)_{n \times n}=\left[\begin{array}{cccc}
a_{11} & a_{12} & \cdots & a_{1 n} \\
a_{21} & a_{22} & \cdots & a_{2 n} \\
\vdots & \vdots & \cdots & \vdots \\
a_{n 1} & a_{n 2} & \cdots & a_{n n}
\end{array}\right], \\
& \mathrm{CI}=\frac{\lambda_{\max }-n}{n-1}, \\
& \mathrm{CR}=\frac{\mathrm{CI}}{\mathrm{RI}}
\end{aligned}
$$

If $\mathrm{CR}<0.10$, then the consistency of general ranking is considered to be acceptable, otherwise the judgment matrix

\begin{tabular}{|c|c|}
\hline Scale & Meaning \\
\hline 1 & $\begin{array}{c}\text { The factors } i \text { and } j \text { are equally important for the upper } \\
\text { level }\end{array}$ \\
\hline 3 & The factor $i$ is slightly more important than factor $j$ \\
\hline 5 & The factor $i$ is clearly more important than factor $j$ \\
\hline 7 & $\begin{array}{c}\text { The factor } i \text { is significantly more important than } \\
\text { factor } j\end{array}$ \\
\hline 9 & The $\mathrm{f}$ \\
\hline 2,4 & $\begin{array}{l}\text { The median of the two adjacent judgments mentioned } \\
\text { above }\end{array}$ \\
\hline & The importance of the $j$ and $i$ factors to the next level \\
\hline
\end{tabular}

TABLE 2: Temperature and wildlife count in the three areas covered by the study.

must be modified. The average consistency indicator, RI, is presented in Table 3.

If the single-level consistency check is passed, the overall consistency model of the entire hierarchy model must then be checked. When $\mathrm{CR}_{p}<0.10$, the consistency of general ranking is acceptable:

$$
\begin{aligned}
& \mathrm{CR}_{x}=\frac{\sum_{i=1}^{n} x_{i} \mathrm{CI}_{i}}{\sum_{i=1}^{n} x_{i}}, \\
& \mathrm{CR}_{y}=\frac{\sum_{i=1}^{n} y_{i} \mathrm{CI}_{i}}{\sum_{i=1}^{n} y_{i} \mathrm{RI}_{i}}, \\
& \mathrm{CR}_{p}=\frac{\mathrm{CR}_{x}}{\mathrm{CR}_{y}} .
\end{aligned}
$$

Thus, when the overall consistency of general ranking is considered to be acceptable, combined weight vectors of the first-level indicators can be obtained by means of weight vector of the target analytic hierarchy process as expressed in the following equation:

$$
W=\left(w_{1}, w_{2}, w_{3}, \ldots, w_{m+s}\right)
$$

5.2. DEA Relative Efficiency Calculation. DEA method is a mathematical programming method suitable for determining the relative efficiency of a set of comparable decisionmaking units [59]. Based on various input and output metrics, the method usually is applied to assess the related benefit or effectiveness of a system [60]. The informatization performance evaluation index is designed to encompass two dimensions with the characteristics of input and output metrics. In this paper, the DEA method is used to normalize the index data, and each relative efficiency index is calculated as the basic data of the fuzzy comprehensive evaluation.

In order to ensure the objectivity and scientific nature of the informatization performance evaluation of the construction industrialization EPC enterprise, the basic enterprise data were obtained using the enterprise survey method. In general, the information department of the enterprise is required to respond to a questionnaire. The most representative $C^{2} R$ model of DEA is then applied to process the data. 
TABle 3: Average random consistency index.

\begin{tabular}{|c|c|c|c|c|c|c|c|c|c|c|c|c|c|c|}
\hline$n$ & 1 & 2 & 3 & 4 & 5 & 6 & 7 & 8 & 9 & 10 & 11 & 12 & 13 & 14 \\
\hline RI & 0 & 0 & 0.52 & 0.89 & 1.12 & 1.26 & 1.36 & 1.41 & 1.46 & 1.49 & 1.52 & 1.54 & 1.56 & 1.58 \\
\hline
\end{tabular}

5.2.1. Selecting the Data Processing Model. The process for selecting the dual model of $C^{2} R$ linear programming model is expressed in the following equation:

$$
\left(D_{C^{2} R}\right) \begin{cases}\min & \theta \\ & \sum_{j=1}^{n} X_{j} \lambda_{j}+s^{-}=\theta X_{0} \\ \text { s.t. } & \sum_{j=1}^{n} Y_{j} \lambda_{j}-s^{+}=Y_{0} \\ & \lambda_{j} \geq 0, j=1,2, \ldots, n, \theta \in E_{1}^{+} .\end{cases}
$$

If $\theta_{0}=1$, and $s^{-}, s^{+}, \theta_{0}, \lambda_{0 j}, j=1,2, \ldots, n$ satisfy $s^{0+}=0$, $s^{0-}=0$, then $\mathrm{DMU}_{j 0}$ can be judged to valid. Thus, the relative efficiency index calculated by the model is qualified.
5.2.2. Building Fuzzy Membership Functions. The relative efficiency index calculated by the $C^{2} R$ model cannot be directly used for FCA evaluation. Thus, it was necessary to construct a fuzzy membership function to calculate the fuzzy relative efficiency index. According to the index value standard and preliminary results of DEA data processing, the following fuzzy membership function was constructed, as expressed in equation (7). Informatization performance was divided into six levels: AAA, AA, A, good, qualified, and unqualified:

$$
f= \begin{cases}(0,0,0,0,0,1), & h_{k j} \in[0.00,0.30], \\ \left(0,0,0,0,1-\frac{0.60-h_{k j}}{0.30}, \frac{0.60-h_{k j}}{0.30}\right), & h_{k j} \in[0.30,0.60] \\ \left(0,0,0,1-\frac{0.80-h_{k j}}{0.20}, \frac{0.80-h_{k j}}{0.20}, 0\right), & h_{k j} \in[0.60,0.80] \\ \left(0,0,1-\frac{0.90-h_{k j}}{0.10}, \frac{0.90-h_{k j}}{0.10}, 0,0\right), & h_{k j} \in[0.80,0.90] \\ \left(0,1-\frac{0.95-h_{k j}}{0.05}, \frac{0.95-h_{k j}}{0.05}, 0,0,0\right), & h_{k j} \in[0.90,0.95] \\ \left(1-\frac{1.00-h_{k j}}{0.05}, \frac{1.00-h_{k j}}{0.05}, 0,0,0,0\right), & h_{k j} \in[0.95,1.00]\end{cases}
$$

Using this fuzzy membership function, the relative efficiency index of each DMU calculated by the $C^{2} R$ model was fuzzified, and the membership degree vector matrix, $R$, of each index was obtained, which was used as data preparation for fuzzy comprehensive evaluation.

\subsection{FCA Evaluation Result Calculation. FCA method is used} to quantitative evaluation based on the membership theory of fuzzy mathematics and uses fuzzy mathematics to make an overall multilayer object evaluation $[61,62]$. In this study, based on the objective data of the second step, the FCA method is deployed in the proposed research to make the informatization performance evaluation results more objective and conform more fully to the actual situation.

Based on the weight calculation and calculation of relative efficiency, the research used the FCA method to conduct a comprehensive informatization performance evaluation and conducted a comparison of the results of each evaluation unit.

The fuzziness of fuzzy membership function can be processed through the relative efficiency index, and the single-indicator fuzzy relation matrix can be constructed, as expressed in the following equation: 


$$
R=\left\{\begin{array}{c}
R_{i 1} \\
R_{i 2} \\
R_{i 3} \\
R_{i 4}
\end{array}\right\}=\left\{\begin{array}{cccc}
r_{11} & r_{12} & \ldots & r_{14} \\
r_{21} & r_{22} & \ldots & r_{24} \\
\vdots & \ldots & \ldots & \vdots \\
r_{m+s, 1} & r_{m+s, 2} & \ldots & r_{m+s, 4}
\end{array}\right\} .
$$

According to the fuzzy relation matrix and its index weights, the fuzzy evaluation results of EPC enterprises' informatization performance was calculated, as expressed in the following equation:

$$
\begin{aligned}
B & =W \times R \\
& =\left(w_{1}, w_{2}, w_{3}, \ldots, w_{m+s}\right) \times\left[\begin{array}{cccc}
r_{11} & r_{12} & \ldots & r_{14} \\
r_{21} & r_{12} & \ldots & r_{14} \\
\vdots & \ldots & \ldots & \vdots \\
r_{m+s, 1} & r_{m+s, 2} & \ldots & r_{m+s, 4}
\end{array}\right] \\
& =\left(b_{1}, b_{2}, b_{3}, b_{4}\right) .
\end{aligned}
$$

By calculating the evaluation results of informatization performance and combining with the DEA evaluation results, comprehensive analysis was conducted.

\section{Case Study}

6.1. Data Collection. In order to understand the actual situation of information construction of construction industrialization enterprises, a rigid selection was carried out based on three principles: (1) the enterprise should be the first or super grade general contractor of housing construction; (2) the enterprise has its own prefabricated component factory; and (3) the enterprise mainly adopts the EPC mode in the projects under construction. For instance, Longxin Group and Shenyang Wanrong modern construction industry, Co., Ltd. Based on the characteristics and scope of business operations, this research identified 30 construction industrialization EPC enterprises with effective responses. The regional distribution of the enterprises is presented in Figure 2. During field research, an interview was conducted with the head of the informatization department, and the "construction industrialization EPC Enterprise Informatization Performance Evaluation Questionnaire" was completed. Therefore, the data obtained through the questionnaire are a direct representation of the actual input and output performance of enterprise informatization construction. Analysis of these data can objectively determine the level of enterprise informatization performance evaluation and define the issues confronted by the enterprise.

In addition, the development of China's construction industrialization is still in its infancy; thus, its promotion

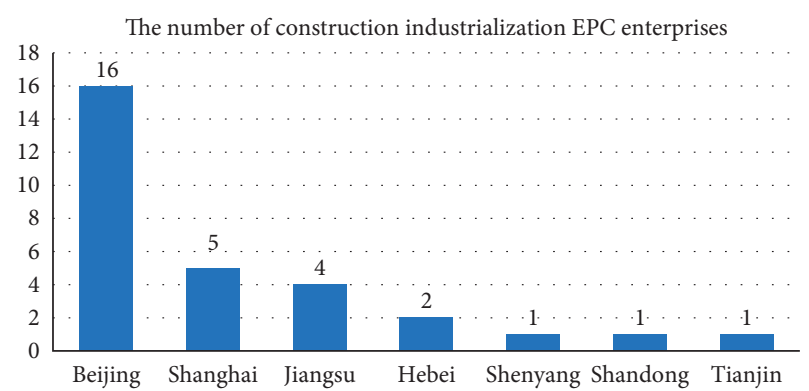

FIGURE 2: Regional distribution mapping of the surveyed enterprises.

focuses on key pilot cities such as Beijing, Shanghai, and Jiangsu. Therefore, the created questionnaire primarily came from the construction industrialization EPC enterprises in the above areas, and the results of the questionnaire distributed focus on these cities.

The data used in this research originated from two sources: (1) the original data provided by the surveyed enterprises and (2) the collected data through a survey.

\subsection{Data Analysis}

6.2.1. Calculating the Weight Value. According to the requirements for the number of expert scores using the AHP method, at least 3 experts with odd numbers are required to ensure reliable results. In this study, five experts, all of whom offer extensive influence and significant experience in the field of construction industrialization, were invited to apply the "1-9 scale method" to the performance evaluation index system. In order to integrate the opinions of different experts, the aggregation method is applied by averaging the response from each expert. Based on the aggregation, the overall weight is obtained for each criterion, and the general ranking weight is also calculated. The yaahp V11.1 software was deployed for data entry and processing.

The process was presented as "constructing judgment matrix $\longrightarrow$ normalizing processing $\longrightarrow$ calculating maximum eigenvalue $\longrightarrow$ hierarchical ordering and consistency checking $\longrightarrow$ hierarchical total ordering and consistency checking $\longrightarrow$ combining weight." The calculation results are provided in Tables 4 and 5 .

The results indicated that the consistency of the firstlevel indicators was checked. The second-level indicators assumed that the 3 plans contributed equally; thus $\mathrm{CR}=0.0000<0.10$ passed the test. Finally, a general ranking and global consistency checking calculation were carried out as follows: 
TABLE 4: Weight index of the evaluation index for construction industrialization enterprise.

\begin{tabular}{|c|c|c|c|c|}
\hline Category & First-level & Weight & Second-level & Weight \\
\hline \multirow{17}{*}{ Input metrics } & \multirow{8}{*}{ Infrastructure establishment $X_{2}$} & \multirow{4}{*}{0.0690} & Informatization planning rationality $X_{11}$ & 0.0074 \\
\hline & & & Informatization management planning investment $X_{12}$ & 0.0190 \\
\hline & & & Organization orientation of informatization department $X_{13}$ & 0.0032 \\
\hline & & & Position and rights of informatization department $X_{14}$ & 0.0049 \\
\hline & & \multirow{4}{*}{0.5565} & Informatization management system integrity $X_{21}$ & 0.0231 \\
\hline & & & Network construction and degree of interconnection $X_{22}$ & 0.0151 \\
\hline & & & Informatization hardware investment $X_{23}$ & 0.1200 \\
\hline & & & Informatization software investment $X_{24}$ & 0.1200 \\
\hline & \multirow{5}{*}{ Team formation $X_{3}$} & \multirow{5}{*}{0.2356} & Informatization team construction $X_{31}$ & 0.0052 \\
\hline & & & Level of leader's information culture $X_{32}$ & 0.0063 \\
\hline & & & Level of employee's information culture $X_{33}$ & 0.0122 \\
\hline & & & Enterprise informatization talent training system $X_{34}$ & 0.0297 \\
\hline & & & Staff information training expenditure $X_{35}$ & 0.0644 \\
\hline & \multirow{4}{*}{ External environmental $X_{4}$} & \multirow{4}{*}{0.1389} & Government-related policies and regulations support $X_{41}$ & 0.0146 \\
\hline & & & Stakeholder information construction $X_{42}$ & 0.0367 \\
\hline & & & Construction bidding environment construction $X_{43}$ & 0.0146 \\
\hline & & & Prefabricated plant site selection $X_{44}$ & 0.0036 \\
\hline \multirow{27}{*}{ Output metrics } & \multirow{11}{*}{ Business process performance $Y_{2}$} & \multirow{3}{*}{0.3687} & Profit rate of main business of the enterprise $Y_{11}$ & 0.0767 \\
\hline & & & The increase of enterprise fund turnover rate $Y_{12}$ & 0.0232 \\
\hline & & & Quantifiable economic benefits $Y_{13}$ & 0.0844 \\
\hline & & \multirow{8}{*}{0.1492} & Human resources management application level $Y_{21}$ & 0.0025 \\
\hline & & & Automation office level $Y_{22}$ & 0.0051 \\
\hline & & & Information system application level $Y_{23}$ & 0.0036 \\
\hline & & & Business process softness $Y_{24}$ & 0.0063 \\
\hline & & & Project informatization application level $Y_{25}$ & 0.0192 \\
\hline & & & Project informatization management level $Y_{26}$ & 0.0254 \\
\hline & & & Industrialization construction settlement improvement $Y_{27}$ & 0.0125 \\
\hline & & & Internal resource integration $Y_{31}$ & 0.0105 \\
\hline & \multirow{4}{*}{ Management performance $Y_{3}$} & \multirow{4}{*}{0.1237} & Standardized degree of informatization management $Y_{32}$ & 0.0023 \\
\hline & & & Scientific of management decision support $Y_{33}$ & 0.0344 \\
\hline & & & Sensitivity to engineering emergencies $Y_{34}$ & 0.0072 \\
\hline & & & Sensitivity to major changes in engineering $Y_{35}$ & 0.0074 \\
\hline & \multirow{3}{*}{ Market performance $Y_{4}$} & \multirow{3}{*}{0.2575} & EPC enterprise market share or status $Y_{41}$ & 0.0921 \\
\hline & & & Market acceptance of industrialized building products $Y_{42}$ & 0.0241 \\
\hline & & & Sensitivity of the enterprise to market change $Y_{43}$ & 0.0126 \\
\hline & \multirow{5}{*}{ Impacts on other stakeholders $Y_{5}$} & \multirow{5}{*}{0.0591} & Increased government satisfaction $Y_{51}$ & 0.0023 \\
\hline & & & Increased supplier satisfaction $Y_{52}$ & 0.0039 \\
\hline & & & Increased customer satisfaction $Y_{53}$ & 0.0137 \\
\hline & & & Increased the third-party agencies satisfaction $Y_{54}$ & 0.0012 \\
\hline & & & Stakeholder coordination and response capabilities $Y_{55}$ & 0.0084 \\
\hline & \multirow{4}{*}{ Learning and growth $Y_{6}$} & \multirow{4}{*}{0.0418} & Types of informatization talents $Y_{61}$ & 0.0123 \\
\hline & & & Employee knowledge innovation ability $Y_{62}$ & 0.0012 \\
\hline & & & Corporate employees' acceptance of information $Y_{63}$ & 0.0043 \\
\hline & & & Project information standard ${ }_{\mathrm{Y} 64}$ & 0.0031 \\
\hline
\end{tabular}

$$
\begin{aligned}
\mathrm{CR}_{X} & =\frac{\sum_{i=1}^{n} x_{i} \mathrm{CI}_{i}}{\sum_{i=1}^{n} x_{i} \mathrm{RI}_{i}}=\frac{0.0690 \times 0.0189+\cdots+0.1389 \times 0.0245}{0.0690 \times 0.8900+\cdots+0.1389 \times 0.8900}=0.0326<0.10, \\
\mathrm{CR}_{Y} & =\frac{\sum_{i=1}^{m} y_{i} \mathrm{CI}_{i}}{\sum_{i=1}^{m} y_{i} \mathrm{RI}_{i}}=\frac{0.3687 \times 0.0046+\cdots+0.0418 \times 0.0593}{0.3687 \times 0.5200+\cdots+0.0418 \times 0.8900}=0.0438<0.10, \\
\mathrm{CR}_{P} & =\frac{\sum_{i=1}^{n+m} w_{i} \mathrm{CI}_{i}}{\sum_{i=1}^{n+m} w \mathrm{RI}_{i}}=\frac{0.0345 \times 0.0189+\cdots+0.1844 \times 0.0046+\cdots+0.0209 \times 0.0593}{0.0345 \times 0.8900+\cdots+0.1844 \times 0.5200+\cdots+0.0209 \times 0.8900}=0.0376<0.10 .
\end{aligned}
$$

From the above results, it can be observed that two levels of indicators for the overall goal pass the global consistency checking. So, the combined weights indicated high validity and reliability. The ranking weight and combination weight of the first-level indicators are presented in Table 6. 
TABle 5: Consistency test of first-level elements with decision objectives $(\mathrm{CR}<0.10)$.

\begin{tabular}{|c|c|c|c|c|c|c|c|c|c|}
\hline$X_{1}$ & $X_{2}$ & $X_{3}$ & $X_{4}$ & $Y_{1}$ & $Y_{2}$ & $Y_{3}$ & $Y_{4}$ & $Y_{5}$ & $Y_{6}$ \\
\hline 0.0212 & 0.0137 & 0.0731 & 0.0275 & 0.0088 & 0.0701 & 0.0770 & 0.0019 & 0.0667 & 0.0666 \\
\hline
\end{tabular}

TABLE 6: Ranking weight and combination weight of first-level indicators.

\begin{tabular}{lcccccccccc}
\hline Second index & $X_{1}$ & $X_{2}$ & $X_{3}$ & $X_{4}$ & $Y_{1}$ & $Y_{2}$ & $Y_{3}$ & $Y_{4}$ & $Y_{5}$ & $Y_{6}$ \\
\hline Weigh & 0.0690 & 0.5565 & 0.2356 & 0.1389 & 0.3687 & 0.1492 & 0.1237 & 0.2575 & 0.0591 & 0.0418 \\
\hline Middle layer & \multicolumn{7}{c}{$X(W=0.5000)$} \\
\hline Weight & 0.0345 & 0.2782 & 0.1178 & 0.0695 & 0.1844 & 0.0746 & 0.0618 & 0.1288 & 0.0295 & 0.0209 \\
Sort & 8 & 1 & 4 & 6 & 2 & 5 & 7 & 3 & 9 \\
\hline
\end{tabular}

The weight of the target combined weights is calculated with the following equation:

$W=(0.0345,0.2782,0.1178,0.0695,0.1844,0.0746,0.0618$,

$$
0.1288,0.0295,0.0209) \text {. }
$$

6.2.2. Constructing Fuzzy Relation Matrix. DEA-Solver Pro 5.0 software was selected as a tool for data processing. Selecting the data processing model of Model Name $=$ DEASolver Pro 5.0/CCR(CCR-I), the original data were processed and calculated. The sample data of the first-level indicators $X=\left[X_{1}, X_{2}, X_{3}, X_{4}\right]$ were utilized as the input metrics (I), and the first-level indicators $Y=\left[Y_{1}, Y_{2}, Y_{3}, Y_{4}\right.$, $\left.Y_{5}, Y_{6}\right]$ were utilized as the output metrics $(\mathrm{O})$. The index value was substituted into the program, and the relative efficiency of DEA and relative efficiency of the first-level indicators of each evaluation unit were calculated. The results are presented in Appendix Table A1.

The relative efficiency value of the first-level indicators of each evaluation unit was fuzzed, thereby introducing the membership degree function to manage the data and obtain the fuzzy membership degree of the relative efficiency of DEA. The vectors were arranged according to the columns, forming the fuzzy relational matrix, $R$, and utilizing DMU3 as an example, and the calculation is as follows:

$$
R_{\mathrm{DMU} 3}=\left\{\begin{array}{c}
R_{i 1} \\
R_{i 2} \\
R_{i 3} \\
R_{i 4} \\
R_{i 5} \\
R_{i 6} \\
R_{i 7} \\
R_{i 8} \\
R_{i 9} \\
R_{i 10}
\end{array}\right\}=\left\{\begin{array}{cccccc}
0 & 0 & 0 & 0.8380 & 0.1620 & 0 \\
0 & 0 & 0 & 0.8380 & 0.1620 & 0 \\
0 & 0 & 0 & 0.8380 & 0.1620 & 0 \\
0 & 0 & 0 & 0.8380 & 0.1620 & 0 \\
0 & 0 & 0 & 0 & 0.3480 & 0.6520 \\
0 & 0 & 0 & 0 & 0 & 1 \\
1 & 0 & 0 & 0 & 0 & 0 \\
0 & 0 & 0 & 0 & 0 & 1 \\
1 & 0 & 0 & 0 & 0 & 0 \\
1 & 0 & 0 & 0 & 0 & 0
\end{array}\right\} .
$$

6.2.3. Calculation of Comprehensive Evaluation Results. The fuzzy comprehensive evaluation matrix, $B=W \times R$, was calculated by using the combined weight vector, $W$, and DEA relative efficiency fuzzy value matrix. The evaluation results of the enterprises were calculated. According to the rank of AAA, AA, A, good, qualified, and unqualified, the evaluation grade was given by adopting the maximum membership degree principle (shown in Table 7), which is summarized in Table 8.

\section{Results and Discussion}

7.1. Analysis of Comprehensive Evaluation Results. From Table 8 , the following observations can be made: (1) a total of 15 enterprises received AAA rating; (2) one enterprise received the grade of $\mathrm{AA}$; (3) two enterprises achieved grade A; (4) seven enterprises received a Good rating; (5) a total of 15 enterprises obtained a Qualified rating; and (6) none of the enterprise's received an evaluation result of Failed.

From the results, it can be observed that among all the 30 enterprises are qualified, and the proportion of information construction at the A level or above accounted for $60 \%$, of which $83.3 \%$ accounted for the industry-leading enterprise information level. This is because construction industrialization is in the initial stage [63], and informatization construction in the early stage has played a positive role in promoting such enterprises [64]. About $40 \%$ of enterprises indicated good performance, which reveals that enterprises need to strengthen their informatization construction, which indirectly reflects the status quo of the primary level of enterprise informatization.

From the analysis of performance value, the highest scores are observed in infrastructure establishment (81.51) and strategic planning (79.88), and their standard deviation (SD) values are small, which indicates that the enterprise informatization is the best in these areas. It also reveals that the informatization construction of China's enterprises is in a period of rapid growth. The score for learning and growth (59.84), external environment (62.63), and team formation (63.43) are the lowest, and the SD value is greater, which indicates that the effect of the informatization performance on these three aspects is bad, and the output effect is uneven. 
TABLE 7: Result evaluation rank interpretation of enterprise informatization performance.

\begin{tabular}{lrr}
\hline Rank & Contents & Situations \\
\hline AAA & Harmonization of input and output in performance & Begin development \\
AA & Basic harmonization of input and output in performance & Begin development \\
A & Basic harmonization of input and output in performance & Normal development \\
Good & The input and output can meet the normal operation & Normal development \\
Qualified & The output and input are inconsistent & Minor adjustment \\
Unqualified & The output and input are inconsistent & Major adjustment \\
\hline
\end{tabular}

TABLE 8: Comprehensive evaluation results of construction industrialization enterprises.

\begin{tabular}{|c|c|c|}
\hline Evaluation unit & Comprehensive evaluation results & Evaluation grade \\
\hline DMU1 & $(\mathbf{1 . 0 0 0 0}, 0.0000,0.0000,0.0000,0.0000,0.0000)$ & AAA \\
\hline DMU2 & $(1.0000,0.0000,0.0000,0.0000,0.0000,0.0000)$ & AAA \\
\hline DMU3 & $(0.0913,0.0000,0.0000, \mathbf{0 . 4 1 8 9}, 0.1453,0.3445)$ & Good \\
\hline DMU4 & $(1.0000,0.0000,0.0000,0.0000,0.0000,0.0000)$ & AAA \\
\hline DMU5 & $(\mathbf{0 . 5 3 0 2}, 0.1195,0.0000,0.0000,0.0508,0.2995)$ & AAA \\
\hline DMU6 & $(1.0000,0.0000,0.0000,0.0000,0.0000,0.0000)$ & AAA \\
\hline DMU7 & $(\mathbf{0 . 6 8 6 3}, 0.0599,0.1150,0.1057,0.0331,0.0000)$ & AAA \\
\hline DMU8 & $(\mathbf{0 . 4 0 3 5}, 0.1044,0.0000,0.3152,0.1769,0.0000)$ & AAA \\
\hline DMU9 & $(1.0000,0.0000,0.0000,0.0000,0.0000,0.0000)$ & AAA \\
\hline DMU10 & $(0.2115,0.0000,0.0000,0.0249, \mathbf{0 . 4 3 2 8}, 0.3308)$ & Qualified \\
\hline DMU11 & $(0.1497,0.0000,0.0323, \mathbf{0 . 3 9 5 0}, 0.2139,0.2092)$ & Good \\
\hline DMU12 & $(0.2053,0.2629, \mathbf{0 . 2 9 9 2}, 0.0755,0.0608,0.0963)$ & A \\
\hline DMU13 & $(1.0000,0.0000,0.0000,0.0000,0.0000,0.0000)$ & AAA \\
\hline DMU14 & $(\mathbf{1 . 0 0 0 0}, 0.0000,0.0000,0.0000,0.0000,0.0000)$ & AAA \\
\hline DMU15 & $(0.3793,0.0166,0.0000,0.1245, \mathbf{0 . 4 1 7 7}, 0.0618)$ & Qualified \\
\hline DMU16 & $(1.0000,0.0000,0.0000,0.0000,0.0000,0.0000)$ & AAA \\
\hline DMU17 & $(0.0913, \mathbf{0 . 3 0 5 1}, 0.0827,0.2178,0.3031,0.0000)$ & $\mathrm{AA}$ \\
\hline DMU18 & $(0.2246,0.0102,0.1056,0.1002, \mathbf{0 . 5 3 4 3}, 0.0251)$ & Qualified \\
\hline DMU19 & $(0.2472,0.0600,0.0821, \mathbf{0 . 4 3 6 7}, 0.1581,0.0159)$ & Good \\
\hline DMU20 & $(0.1122,0.1128,0.0160,0.0150, \mathbf{0 . 6 2 5 1}, 0.1188)$ & Qualified \\
\hline DMU21 & $(0.0250,0.1247,0.0000, \mathbf{0 . 3 5 6 2}, 0.3080,0.1861)$ & Good \\
\hline DMU22 & $(1.0000,0.0000,0.0000,0.0000,0.0000,0.0000)$ & AAA \\
\hline DMU23 & $(0.3750,0.0236,0.0059, \mathbf{0 . 4 6 2 6}, 0.1329,0.0000)$ & Good \\
\hline DMU24 & $(1.0000,0.0000,0.0000,0.0000,0.0000,0.0000)$ & AAA \\
\hline DMU25 & $(0.3503,0.0000,0.0752, \mathbf{0 . 4 6 0 7}, 0.0929,0.0209)$ & Good \\
\hline DMU26 & $(0.2799,0.1635, \mathbf{0 . 3 4 7 5}, 0.1486,0.0310,0.0295)$ & A \\
\hline DMU27 & $(1.0000,0.0000,0.0000,0.0000,0.0000,0.0000)$ & AAA \\
\hline DMU28 & $(0.2462,0.0000,0.0000, \mathbf{0 . 5 5 1 1}, 0.0433,0.1594)$ & Good \\
\hline DMU29 & $(\mathbf{1 . 0 0 0 0}, 0.0000,0.0000,0.0000,0.0000,0.0000)$ & AAA \\
\hline DMU30 & $(0.2201,0.0000,0.0676,0.0070, \mathbf{0 . 4 4 0 0}, 0.2653)$ & Qualified \\
\hline
\end{tabular}

7.2. Analysis of DEA Evaluation Results. By collating the data collected by the enterprise questionnaire and applying DEA software, the following calculated results were obtained. The results are presented in Tables 9-11.

From the summary of the software processing results, it can be observed that there are 12 sample enterprises where DEA is valid: DMU1, DMU2, DMU4, DMU6, DMU9, DMU13, DMU14, DMU16, DMU22, DMU24, DMU27, and DMU29. The DEA relative efficiency of DMU5, DMU7, and DMU8 is near to 1 , which is nearly valid, and it is consistent with the AAA-rating enterprise of D-FCA comprehensive evaluation. The ratings of other companies are also consistent with their DEA relative efficiency.

7.2.1. Correlation Analysis. From Table 11, it can be observed that strategic planning played a significant role in
TABLE 9: Basic situation of data processing.

\begin{tabular}{lcc}
\hline No. & Category & Scores \\
\hline 1 & No. of DMUs in data & 30 \\
2 & No. of DMUs with inappropriate data & 0 \\
3 & No. of evaluated DMUs & 30 \\
4 & Average of scores & 0.94645 \\
5 & No. of efficient DMUs & 12 \\
6 & No. of inefficient DMUs & 18 \\
7 & No. of over iteration DMUs & 0 \\
\hline
\end{tabular}

informatization construction such that there is a direct guideline for enterprise development, which can be obtained from the correlation of business process performance (0.5424), management performance (0.3911), and external environment (0.3092). Infrastructure establishment has a strong correlation with market performance (0.3394), 


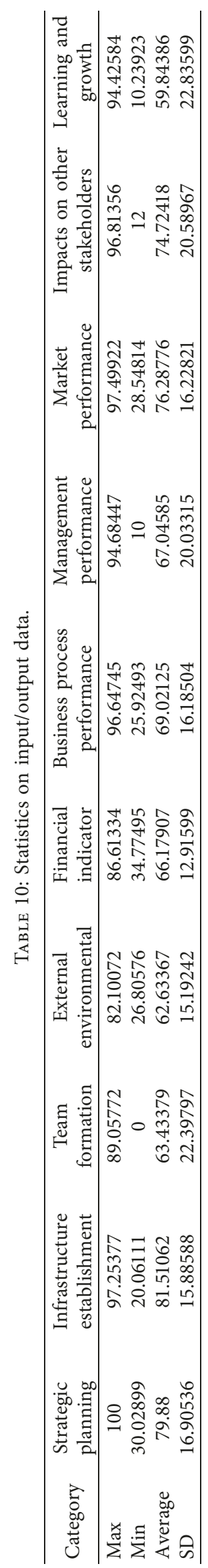




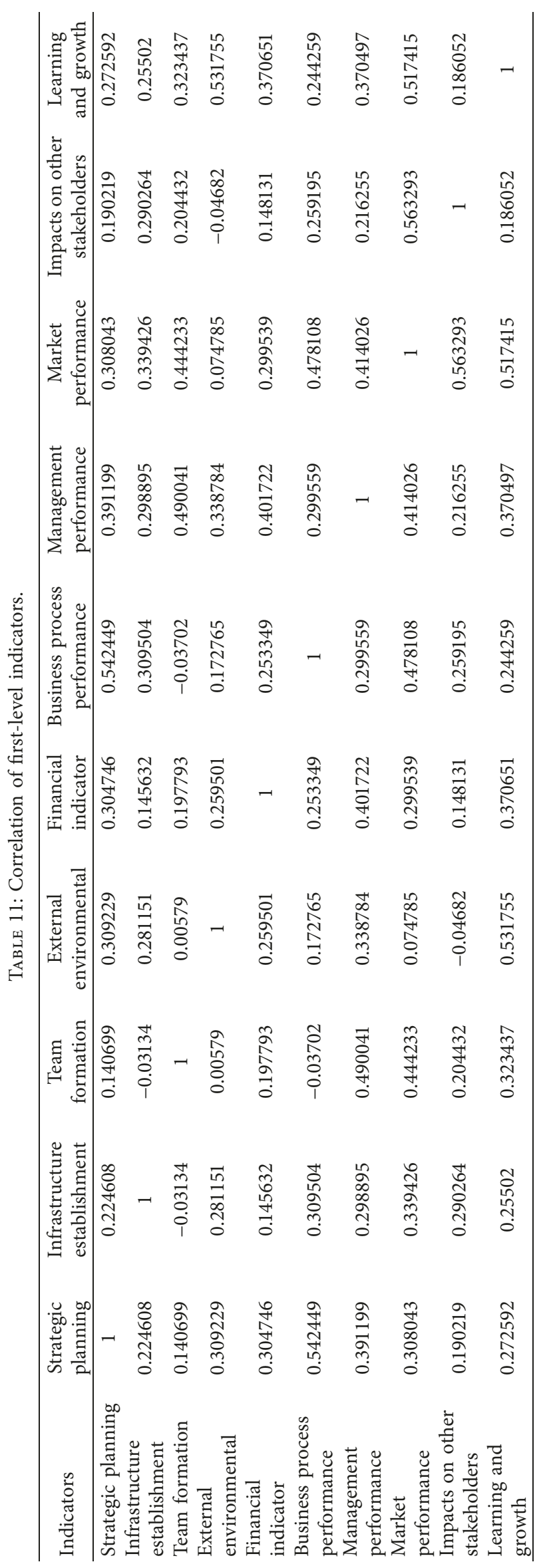


TABLE 12: Specific improvement measures for DMU3.

\begin{tabular}{|c|c|c|c|c|}
\hline DMU I/O & Score data & Projection & Difference & $\%$ \\
\hline DMU 3 & 0.91557 & - & - & - \\
\hline Strategic planning & 87.37681 & 79.99937 & -7.37745 & -8.44 \\
\hline Infrastructure establishment & 71.90151 & 65.83068 & -6.07083 & -8.44 \\
\hline Team formation & 74.70289 & 68.39553 & -6.30735 & -8.44 \\
\hline External environmental & 51.48201 & 47.13526 & -4.34676 & -8.44 \\
\hline Financial indicator & 50.36659 & 63.48938 & 13.12279 & 26.05 \\
\hline Business process performance & 54.65147 & 77.54062 & 22.88914 & 41.88 \\
\hline Management performance & 71.31068 & 71.31068 & 0 & 0.00 \\
\hline Market performance & 35.31056 & 85.94299 & 50.63243 & 143.39 \\
\hline Impacts on other stakeholders & 83.55254 & 83.55254 & 0 & 0.00 \\
\hline Learning and growth & 36.17225 & 52.75407 & 16.58182 & 45.84 \\
\hline
\end{tabular}

TABle 13: Specific improvement measures for DMU10.

\begin{tabular}{|c|c|c|c|c|}
\hline DMU I/O & Score data & Projection & Difference & $\%$ \\
\hline DMU10 & 0.78683 & - & - & - \\
\hline Strategic planning & 56.43478 & 44.40478 & -12.03 & -21.32 \\
\hline Infrastructure establishment & 94.50755 & 68.14699 & -26.3606 & -27.89 \\
\hline Team formation & 61.57046 & 48.4457 & -13.1248 & -21.32 \\
\hline External environmental & 56.80576 & 44.69667 & -12.1091 & -21.32 \\
\hline Financial indicator & 49.11876 & 56.1949 & 7.076139 & 14.41 \\
\hline Business process performance & 57.18499 & 67.1388 & 9.953809 & 17.41 \\
\hline Management performance & 49.30421 & 49.30421 & 0 & 0.00 \\
\hline Market performance & 67.88354 & 67.88354 & 0 & 0.00 \\
\hline Impacts on other stakeholders & 56.61017 & 79.24868 & 22.63851 & 39.99 \\
\hline Learning and growth & 50.04785 & 50.04785 & 0 & 0.00 \\
\hline
\end{tabular}

business process performance (0.3095), and management performance (0.2989), indicating that the enterprise's informatization infrastructure is the basis for business, and it is also the basis for market expansion. It is worth mentioning that infrastructure establishment and team formation $(-0.0313)$ are negatively related, indicating that team formation investment with software and hardware investment is in conflict. Team formation has a strong correlation with market performance $(0.4442)$, management performance (0.4900), and learning and growth (0.3234) because the information quality of senior management and employees is enhanced, and the enterprise management plays a catalytic role, which will certainly improve the enterprise's learning and innovation capabilities. External environmental is strongly related to learning and growth (0.5317) and management performance (0.3388). It can be explained that government policy support and informatization construction of other stakeholders have played a key role in the growth processing. Financial indicators are closely related to management performance (0.4017), learning and growth (0.3707), and market performance (0.2995) because the rapid operation of enterprises' funds and high-yield businesses has contributed to the market growth and expansion. Business process performance is strongly related to market performance (0.4781) and management performance (0.3000). Considering the day-to-day business operations, it can be ascertained that internal management and external market are directly related. Management performance is strongly related to market performance $(0.4140)$ because the enterprise achievement of increasing market share cannot be separated from the effective management. Market performance is strongly related to impacts on other stakeholders (0.5633) and learning and growth (0.5174) because the partners' market support is critical for market development. And since the market is the source of external resources, it is also the base for learning and growth.

7.2.2. Mapping Analysis of Single Enterprise. The DEA's ineffective construction industrialization EPC enterprises include DMU3, DMU5, DMU7, DMU8, DMU10, DMU11, DMU12, DMU15, DMU17, DMU18, DMU19, DMU20, DMU21, DMU23, DMU25, DMU26 DMU28, and DMU30. By adjusting corresponding index items to achieve the consistency of input and output, the maximization of enterprise informatization performance can be achieved.

The evaluation score of DMU3 is neither the highest nor the lowest; thus it is the most representative. While the score of DMU10 is the lowest, its effect of adjustment measures is clear. Thus, taking the evaluation units DMU3 and DMU10 as examples to analyse, the specific adjustment measures are presented in Tables 12 and 13.

As presented in Table 12, the relative efficiency index of DMU3 is near to 1 , and its score is 0.91557 . So, DMU3 has not yet achieved the best performance of informatization construction, and improvements can be made. As per analysis from the angle of a single indicator score, its early investment is relatively large, but the late output is 
insufficient. Thus, some recommendations can be made to achieve the consistency of input and output of enterprise informatization for DMU3: (1) by reducing investment in strategic planning, infrastructure establishment, team formation, and external environmental aspects, the input proportion can be reduced by about $8.4 \%$; (2) for output metrics, it should increase investment in the areas of financial indicator, business process performance, market performance, and learning and growth, and the increased proportions were $26.05 \%, 41.88 \%, 143.39 \%$, and $45.84 \%$, respectively; and (3) its other indicators can remain unchanged.

From Table 13, it can be observed that the relative efficiency index of DMU10 is less than 1, and its score is 0.78683 . Overall, its informatization construction is characterized by early investment redundancy. From the input indicators analysis, the enterprise needs to reduce investments by $21.32 \%$, while the indicator of infrastructure establishment should be reduced by $27.89 \%$. In terms of output indicators, the enterprise performs well in the areas of management performance, market performance, and learning and growth, while it should be intensified in the areas of financial indicator, business process performance, and impacts on other stakeholders, by an increasing proportion of $14.41 \%, 17.41 \%$, and $39.99 \%$, respectively.

\section{Conclusions}

The informatization of construction industrialization enterprises in China is receiving increasing attention, and an enormous amount of investment has been spent towards informatization management of construction industrialization in China. However, the performance and outputs of industrialization enterprise informatization remain uncertain. This paper constructed an informatization evaluation framework for China's construction industrialization EPC enterprises based on informalization "input-output". Qualitative and quantitative studies are applied to evaluate the informatization performance: (1) the index system of informatization performance evaluation is established through qualitative studies and (2) a mixed quantitative method is applied to evaluate the informatization performance of construction industrialization EPC enterprises. Finally, case studies are conducted for the model application and validation of 30 enterprises in China.

The index framework is sorted and integrated by referring to the performance prism method and the national enterprise informatization evaluation index system. The index system entails a hierarchical input and output structure, i.e., the input metrics include 4 first-level and 17 second-level indicators, and the output metrics include 6 first-level and 27 second-level indicators, respectively. A survey is conducted to collect data within 30 enterprises in China. Based on the collected data, a combined method (improved D-FCA) is proposed to evaluate the overall informalization performance of construction industrialization EPC enterprises in China, which incorporates that (1) the AHP method is used to determine the weight of the evaluation indicators, (2) the DEA method is used to calculate the relative efficiency index of each enterprise, and (3) the FCA method is used to calculate the comprehensive evaluation results.

The evaluation results showed that the informatization of construction industrialization EPC enterprises is currently in the process of rapid development. All the surveyed enterprises met the performance requirement, and $60 \%$ of the thirty enterprises showed excellent performance, reaching A level, AA level, and AAA level. Correlation analysis of the single indicator is also conducted, based on which it was found that strategic planning, which played a significant role in guiding construction of enterprise informatization, has a strong correlation with business process performance, management performance, and external environment. In addition, by comparing average scores and SD values, it can be concluded that external environment, market performance, impacts on other stakeholders, and learning and growth have a smaller score and SD values, and specific attention should be given for them to improve their performance. Furthermore, for the enterprises with DEA scores less than 1, several specific adjustment measures are recommended to reach the performance maximization. This study contributes a comprehensive framework to the informatization evaluation of construction industrialization EPC enterprises in China, which can help enterprisers understand the current situation and shortcomings of their informatization construction and provide specific strategies to improve the performance.

The enterprises studied in this paper mainly come from some developed areas in China; due to the current status of giving priority to the development of construction industrialization in Beijing, Shanghai and other developed areas, the overall situation for construction industrialization needs to be further studied in future research with the rapid development of construction industrialization and informalization. In addition, more advanced methods can be selected in data processing.

\section{Data Availability}

The data used to support the findings of this study are included within the article.

\section{Conflicts of Interest}

The authors declare that they have no conflicts of interest.

\section{Acknowledgments}

This work was supported by the National Key R\&D Program of China (2016YFC0701810 in 2016YFC0701800), the Yujie Talent Project of NCUT (grant number 107051360019XN134/ 006), the Innovative Engineering Project of NCUT (grant number 110051360019XN120), and the Project of National Social Science Foundation of China (71401002).

\section{Supplementary Materials}

Table A1: DEA relative efficiency value of first-level index of each DMU. (Supplementary Materials) 


\section{References}

[1] Y. Teng, C. Mao, G. Liu, and X. Wang, "Analysis of stakeholder relationships in the industry chain of industrialized building in China," Journal of Cleaner Production, vol. 152, pp. 387-398, 2017.

[2] Y. Teng, K. Li, W. Pan, and T. Ng, "Reducing building life cycle carbon emissions through prefabrication: evidence from and gaps in empirical studies," Building and Environment, vol. 132, pp. 125-136, 2018.

[3] I. J. Ramaji and A. M. Memari, "Product architecture model for multistory modular buildings," Journal of Construction Engineering and Management, vol. 142, no. 10, 2016.

[4] S. Aram, C. Eastman, and R. Sacks, "Requirements for BIM platforms in the concrete reinforcement supply chain," $A u$ tomation in Construction, vol. 35, pp. 1-17, 2013.

[5] M. D. Taylor, "A definition and valuation of the UK offsite construction sector," Construction Management and Economics, vol. 28, no. 8, pp. 885-896, 2010.

[6] D. Arditi and K. Mochtar, "Trends in productivity improvement in the US construction industry," Construction Management and Economics, vol. 18, no. 1, pp. 15-27, 2000.

[7] X. Zhang, M. Skitmore, and Y. Peng, "Exploring the challenges to industrialized residential building in China," Habitat International, vol. 41, pp. 176-184, 2014.

[8] H. Said, "Prefabrication best practices and improvement opportunities for electrical construction," Journal of Construction Engineering and Management, vol. 141, no. 12, p. 14, 2015.

[9] W. Zhang, M. W. Lee, L. Jaillon, and C.-S. Poon, "The hindrance to using prefabrication in Hong Kong's building industry," Journal of Cleaner Production, vol. 204, pp. 70-81, 2018.

[10] J. Hong, G. Q. Shen, Z. Li, B. Zhang, and W. Zhang, "Barriers to promoting prefabricated construction in China: a costbenefit analysis," Journal of Cleaner Production, vol. 172, pp. 649-660, 2018.

[11] W. Pan, A. G. F. Gibb, and A. R. J. Dainty, "Strategies for integrating the use of off-site production technologies in house building," Journal of Construction Engineering and Management, vol. 138, no. 11, pp. 1331-1340, 2012.

[12] X. Cao, X. Li, Y. Zhu, and Z. Zhang, "A comparative study of environmental performance between prefabricated and traditional residential buildings in China," Journal of Cleaner Production, vol. 109, pp. 131-143, 2015.

[13] Y. Ji, K. Li, G. Liu, A. Shrestha, and J. Jing, "Comparing greenhouse gas emissions of precast in-situ and conventional construction methods," Journal of Cleaner Production, vol. 173, pp. 124-134, 2018.

[14] MOHURD, "From january to october 2017, the newly built assembly buildings nationwide will be 127-200 million," Journal of Building Technology, vol. 49, no. 1, p. 8, 2017.

[15] Y. B. Ji, F. Y. Yao, and W. J. Tong, "Design and application of performance evaluation index system of assembly building \& EPC enterprise informatization," Science and Technology Management Research, vol. 38, no. 11, pp. 188-194, 2018.

[16] M. Aldhaheri, A. Bakchan, and M. A. Sandhu, "A structural equation model for enhancing effectiveness of engineering, procurement and construction (EPC) major projects: enduser's perspective," Engineering, Construction and Architectural Management, vol. 25, no. 9, pp. 1226-1252, 2018.

[17] A. Hanna, F. Boodai, and M. El Asmar, "State of practice of building information modeling in mechanical and electrical construction industries," Journal of Construction Engineering and Management, vol. 139, no. 10, Article ID 04013009, 2013.

[18] A. Gerbov, V. Singh, and M. Herva, "Challenges in applying design research studies to assess benefits of BIM in infrastructure projects: reflections from Finnish case studies," Engineering, Construction and Architectural Management, vol. 25 , no. 1 , pp. 2-20, 2018.

[19] J. F. Zhang, Z. J. Wu, P. F. Feng, and D. W. Yu, "Evaluation systems and methods of enterprise informatization and its application," Expert Systems with Applications, vol. 38, no. 7, pp. 8938-8948, 2011.

[20] M. E. Porter and V. E. Millar, How Information Gives You Competitive Advantage, Harvard Business Review Reprint Service, Brighton, UK, 1985.

[21] R. M. Stair, Sistemas de Informação: Uma Abordagem Gerencial, Vol. 4, Livros Técnicos e Científicos, São Paulo, Brasil, 1998.

[22] D. Romero and F. Vernadat, "Enterprise information systems state of the art: past, present and future trends," Computers in Industry, vol. 79, pp. 3-13, 2016.

[23] J. Wang, F. Zeng, and Z. Guo, "The evaluation of enterprise informatization risk based on the unascertained method," Physics Procedia, vol. 25, pp. 492-498, 2012.

[24] L. Zhang and L. Dong, "Application study on building information model (BIM) standardization of Chinese engineering breakdown structure (EBS) coding in life cycle management processes," Advances in Civil Engineering, vol. 2019, Article ID 1581036, 10 pages, 2019.

[25] E. Papadonikolaki, A. Verbraeck, and H. Wamelink, "Formal and informal relations within BIM-enabled supply chain partnerships," Construction Management and Economics, vol. 35, no. 8-9, pp. 531-552, 2017.

[26] H.-H. Yoo and S.-S. Kim, "Construction of facilities management system combining video and geographical information," KSCE Journal of Civil Engineering, vol. 8, no. 4, pp. 435-442, 2004.

[27] J. J. Shi and D. W. Halpin, "Enterprise resource planning for construction business management," Journal of Construction Engineering and Management, vol. 129, no. 2, pp. 214-221, 2003.

[28] Y. Gu, L. Qi, and J. Wang, "Breaking the monolith: strategy, variety, and performance of enterprise information systems," Journal of Systems Science and Systems Engineering, vol. 27, no. 6, pp. 727-770, 2017.

[29] O. Turetken, J. Ondracek, and W. Ijsselsteijn, "Influential characteristics of enterprise information system user interfaces," Journal of Computer Information Systems, vol. 59, no. 3, pp. 243-255, 2017.

[30] Y. Zelenkov, "Agility of enterprise information systems: a conceptual model, design principles and quantitative measurement," Business Informatics, vol. 2018, no. 2, pp. 30-44, 2018.

[31] L. Mu and C. K. Kwong, "A multi-objective optimization model of component selection in enterprise information system integration," Computers \& Industrial Engineering, vol. 115, pp. 278-289, 2018.

[32] B. H. Goh, "Creating intelligent enterprises in the Singapore construction industry to support a knowledge economy," Building and Environment, vol. 41, no. 3, pp. 367-379, 2006.

[33] P. F. Li, S. Q. Zheng, H. Y. Si, and K. Xu, "Critical challenges for BIM adoption in small and medium-sized enterprises: evidence from China," Advances in Civil Engineering, vol. 2019, Article ID 9482350, 14 pages, 2019. 
[34] M. P. Méxas, O. L. G. Quelhas, and H. G. Costa, "Prioritization of enterprise resource planning systems criteria: focusing on construction industry," International Journal of Production Economics, vol. 139, no. 1, pp. 340-350, 2012.

[35] Z. You and C. Wu, "A framework for data-driven informatization of the construction company," Advanced Engineering Informatics, vol. 39, pp. 269-277, 2019.

[36] Y. Hong, A. W. A. Hammad, and A. Akbarnezhad, "Impact of organization size and project type on BIM adoption in the Chinese construction market," Construction Management and Economics, vol. 37, no. 11, pp. 675-691, 2019.

[37] Y. Ji, S. Chang, Y. Qi, Y. Li, H. X. Li, and K. Qi, “A BIM-based study on the comprehensive benefit analysis for prefabricated building projects in China," Advances in Civil Engineering, vol. 2019, Article ID 3720191, 13 pages, 2019.

[38] A. N. Hasan and S. M. Rasheed, "The benefits of and challenges to implement 5D BIM in construction industry," Civil Engineering Journal, vol. 5, no. 2, p. 412, 2019.

[39] T. W. Kang and H. S. Choi, "BIM-based data mining method considering data integration and function extension," KSCE Journal of Civil Engineering, vol. 22, no. 5, pp. 1523-1534, 2017.

[40] Y. Jeong, "A study on the BIM evaluation, analytics, and prediction (EAP) framework and platform in linked building ontologies and reasoners with clouds," Advances in Civil Engineering, vol. 2018, Article ID 5478381, 14 pages, 2018.

[41] M. Bilal, L. O. Oyedele, J. Qadir et al., "Big data in the construction industry: a review of present status, opportunities, and future trends," Advanced Engineering Informatics, vol. 30, no. 3, pp. 500-521, 2016.

[42] N. Yang and IOP, "Evaluation research of small and mediumsized enterprise informatization on big data," in Proceedings of the 2017 2nd International Seminar on Advances in Materials Science and Engineering, Singapore, July 2017.

[43] H. W. Zhu, M. Li, and L. Wu, "The evaluation index system of enterprise informatization based on competition principle," in Proceedings of the 2008 International Conference on Management Science and Engineering 15th Annual Conference Proceedings, H. Lan, Ed., pp. 64-71, Long Beach, CA, USA September 2008.

[44] C. Huai-li, M. Deng-zhe, and F. Fei-ya, "A methodology for evaluating enterprise informatisation in Chinese manufacturing enterprises," The International Journal of Advanced Manufacturing Technology, vol. 23, no. 7-8, pp. 541-545, 2004.

[45] D. Chand, G. Hachey, J. Hunton, V. Owhoso, and S. Vasudevan, "A balanced scorecard based framework for assessing the strategic impacts of ERP systems," Computers in Industry, vol. 56, no. 6, pp. 558-572, 2005.

[46] S.-G. Chen and Y.-K. Lin, "On performance evaluation of ERP systems with fuzzy mathematics," Expert Systems with Applications, vol. 36, no. 3, pp. 6362-6367, 2009.

[47] Y.-C. Shen, P.-S. Chen, and C.-H. Wang, "A study of enterprise resource planning (ERP) system performance measurement using the quantitative balanced scorecard approach," Computers in Industry, vol. 75, pp. 127-139, 2016.

[48] S.-G. Chen and Y.-K. Lin, "An evaluation method for enterprise resource planning systems," Journal of the Operations Research Society of Japan, vol. 51, no. 4, pp. 299-309, 2008.

[49] S. H. Amin and J. Razmi, "An integrated fuzzy model for supplier management: a case study of ISP selection and evaluation," Expert Systems with Applications, vol. 36, no. 4, pp. 8639-8648, 2009.
[50] Q. An, F. Meng, and B. Xiong, "Interval cross efficiency for fully ranking decision making units using DEA/AHP approach," Annals of Operations Research, vol. 271, no. 2, pp. 297-317, 2018.

[51] X. He and J. Zhang, "Supplier selection study under the respective of low-carbon supply chain: a hybrid evaluation model based on FA-DEA-AHP," Sustainability, vol. 10, no. 3, 2018.

[52] D. Yang and C. M. Mak, "An assessment model of classroom acoustical environment based on fuzzy comprehensive evaluation method," Applied Acoustics, vol. 127, pp. 292-296, 2017.

[53] E. Severgnini, E. Galdaméz, and R. Moraes, "Satisfaction and contribution of stakeholders from the performance prism model," Brazilian Business Review, vol. 15, no. 2, pp. 120-134, 2018.

[54] J. J. Molwus, B. Erdogan, and S. Ogunlana, "Using structural equation modelling (SEM) to understand the relationships among critical success factors (CSFs) for stakeholder management in construction," Engineering, Construction and Architectural Management, vol. 24, no. 3, pp. 426-450, 2017.

[55] W. Pan, A. R. J. Dainty, and A. G. F. Gibb, "Establishing and weighting decision criteria for building system selection in housing construction," Journal of Construction Engineering and Management, vol. 138, no. 11, pp. 1239-1250, 2012.

[56] S.-Y. Kim and V. T. Nguyen, "An AHP framework for evaluating construction supply chain relationships," KSCE Journal of Civil Engineering, vol. 22, no. 5, pp. 1544-1556, 2017.

[57] T. L. Saaty, "Decision making with the analytic hierarchy process," International Journal of Services Sciences, vol. 1, no. 1, pp. 83-98, 2008.

[58] T. Chen, Y. Jin, X. Qiu, and X. Chen, "A hybrid fuzzy evaluation method for safety assessment of food-waste feed based on entropy and the analytic hierarchy process methods," Expert Systems with Applications, vol. 41, no. 16, pp. 7328-7337, 2014.

[59] E. H. Lee, H. Lee, S.-Y. Kho, and D.-K. Kim, "Evaluation of transfer efficiency between bus and subway based on data envelopment analysis using smart card data," KSCE Journal of Civil Engineering, vol. 23, no. 2, pp. 788-799, 2018.

[60] X. Zhu, P. Zhang, Y. Wei, Y. Li, and H. Zhao, "Measuring the efficiency and driving factors of urban land use based on the DEA method and the PLS-SEM model-a case study of 35 large and medium-sized cities in China," Sustainable Cities and Society, vol. 50, 2019.

[61] X. G. Wang, "Analysis of factors affecting tropical fruit prices and value chain appreciation strategy based on fuzzy comprehensive evaluation method," Basic \& Clinical Pharmacology \& Toxicology, vol. 123, pp. 84-85, 2018.

[62] D. He and Q. Zhang, "The application of analytic hierarchy process and fuzzy comprehensive evaluation method for the evaluation of enterprise training effectiveness," International Journal of Computational Science and Engineering, vol. 14, no. 2, pp. 126-134, 2017.

[63] Z. Ding, J. Zuo, J. Wu, and J. Wang, "Key factors for the BIM adoption by architects: a China study," Engineering, Construction and Architectural Management, vol. 22, no. 6, pp. 732-748, 2015.

[64] J. Rogers, H.-Y. Chong, and C. Preece, "Adoption of building information modelling technology (BIM): perspectives from Malaysian engineering consulting services firms," Engineering, Construction and Architectural Management, vol. 22, no. 4, pp. 424-445, 2015. 


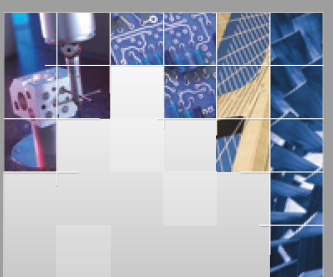

\section{Enfincering}
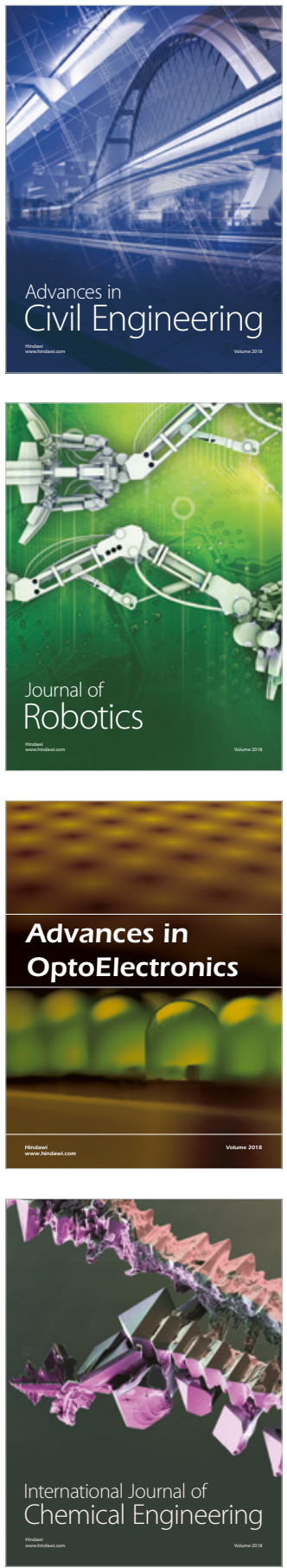

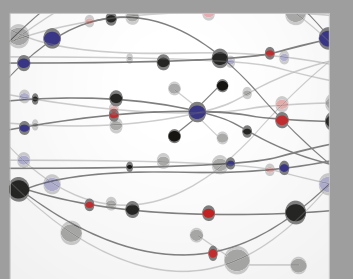

\section{Rotating \\ Machinery}

The Scientific World Journal

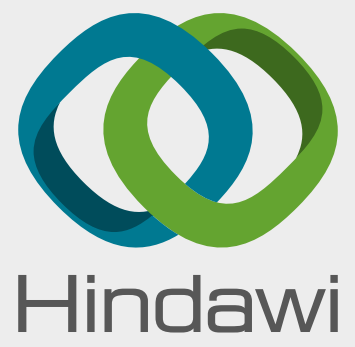

Submit your manuscripts at

www.hindawi.com
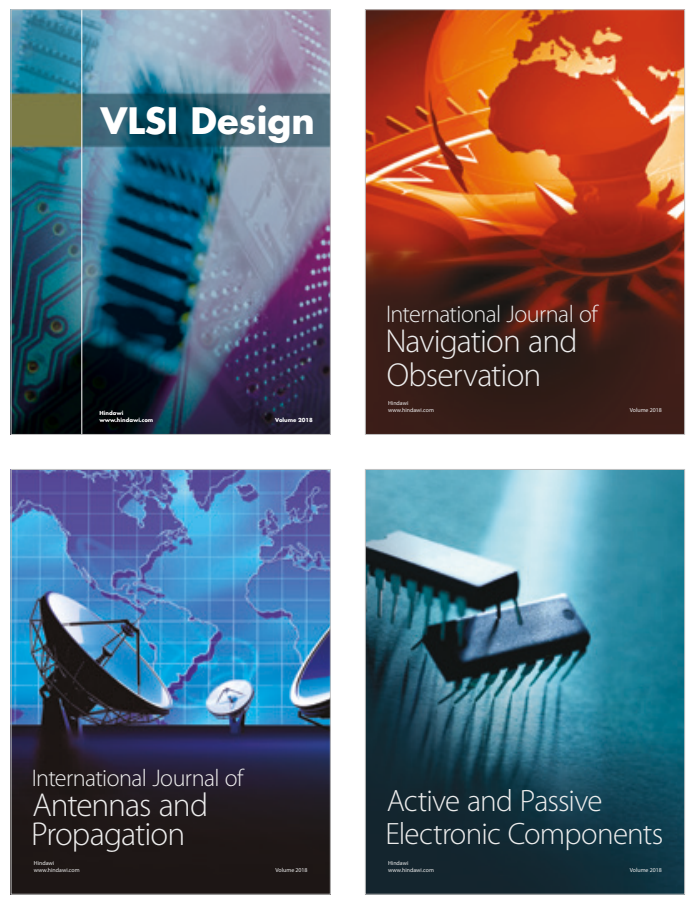
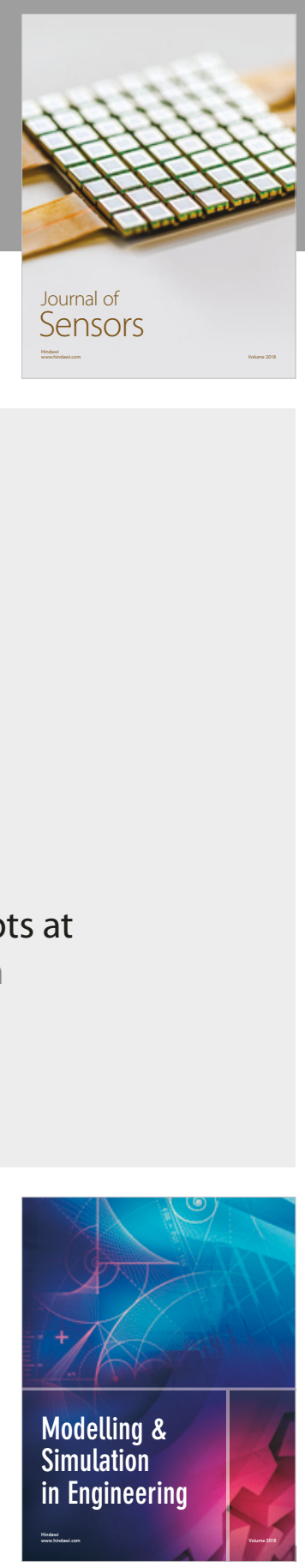

\section{Advances \\ Multimedia}
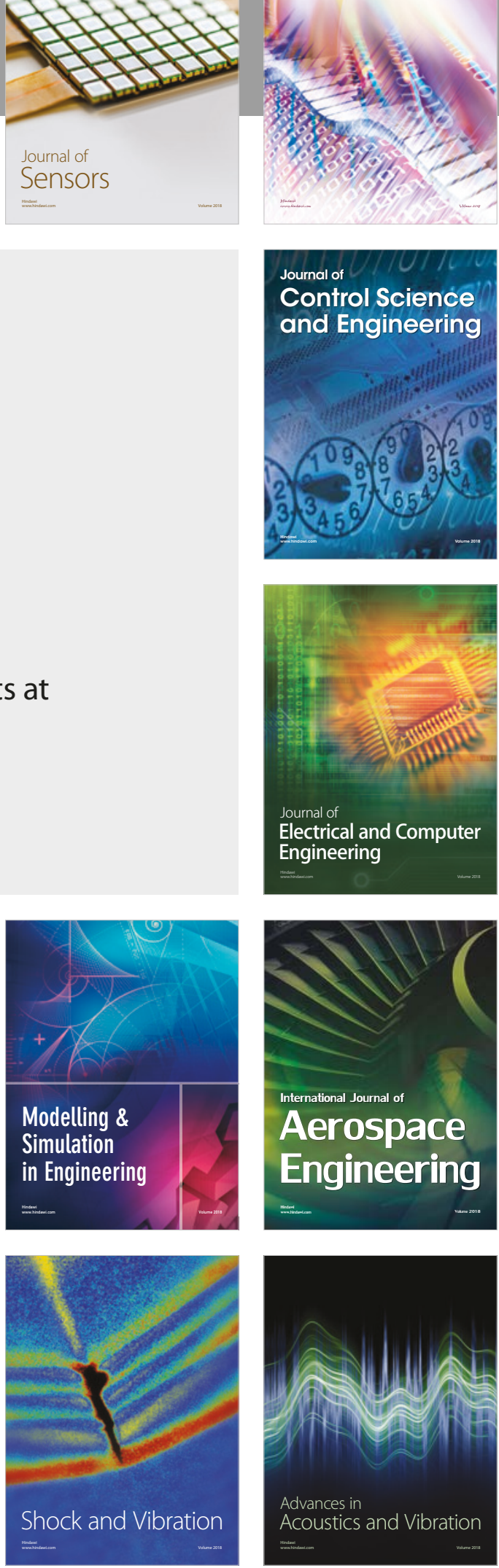